九州大学学術情報リポジトリ

Kyushu University Institutional Repository

\title{
A Study on the Bending Properties of Traditional Korean Joints
}

\section{Kim, Gwang-Chul}

Department of Housing environmental design, College of Human Ecology, Chonbuk National University

Matsumura, Junj i Laboratory of Wood Science, Division of Sustainable Bioresources Science, Faculty of Agriculture, Kyushu University

https://doi.org/10.5109/20331

出版情報 : 九州大学大学院農学研究院紀要. 56 (2)，pp. 353-360，2011-09. Faculty of Agriculture， Kyushu University

バージョン:

権利関係: 


\title{
A Study on the Bending Properties of Traditional Korean Joints
}

\author{
Gwang-Chul KIM ${ }^{1}$ and Junji MATSUMURA ${ }^{2}$
}

\author{
Laboratory of Wood Science, Division of Sustainable Bioresources Science, \\ Faculty of Agriculture, Kyushu University, Fukuoka 812-8581, Japan \\ (Received May 6, 2011 and accepted May 9, 2011)
}

\begin{abstract}
Since an apprentice system was prevalent in Korea instead of the transfer of systematical and scientific theories and techniques for traditional constructions. Therefore, few data have been accumulated for the mechanical and physical properties of traditional joints. The Joomeokjang and Nabijang joints are the most basic jointing method in Korea traditional building construction. In this study, the bending performances for four types of widely used Korean traditional joint, Joomeokjang, Nabijang, pair of double Joomeokjang and cross shaped joint, were evaluated.

The MOR of Nabijang was higher than that of Joomeokjang, and the MOE of Joomeokjang was higher than that of Nabijang; however, there were no significant differences between the two methods. Therefore, the performance of Joomeokjang and Nabijang could not be compared only with the mean values, and additional information such as failure type is necessary. The pair of double Joomeokjang was statistically superior to the cross shape joint in terms of both mean values and the statistical analysis for MOE and MOR. Needless to say, the failure types of machoom joints should be sufficiently considered such as ieum joints. The failure types of Joomeokjang and Nabijang mainly consisted of cross grain failure. Simple tension failure was developed in the pair of double Joomeokjang and cross shaped joints, which created a mixed failure of simple tension failure and cross grain failure.
\end{abstract}

Keywords: ieum joints, machoom joints, Joomeokjang, Nabijang, pair of double Joomeokjang, cross shape joint

\section{INTRODUCTION}

Hanok, a Korean traditional construction, is built by closely fitting the elements together with a machoom (a kind of joint with various angles) or ieum (a kind of longitudinal join) that is different from western construction using nails and adhesives. Hanok is well recognized as a solid and durable house. Hanok will never collapse even if one post is missed due to the inherent advantage of closely fitting the elements together with a machoom or ieum method. Hanok is an earthquake resistant building because of these aspects of its unique construction methods. Hanok is constructed with only ieum and machoom of tenon or mortise, with nails never being used in any joints beyond the roof assembly construction.

There is a proverb that states "without the error of single Chi" in Korea. Chi is a unit of length that corresponds to $3.303 \mathrm{~cm}$. This expression stems from the fact that just one Chi of error is allowable to build a Hanok. An error of about $3 \mathrm{~cm}$ would not be permitted in modern constructions but is permissible in Korean traditional constructions and wood joint constructions. The shrinkage and twisting during drying that is a characteristic of wood has supported a stereotype of Hanok as a poor heating system. Outer wind can often enter through the cleavages that often develop due to shrinkage and twisting, leading to a cold house. Of course, modern techni-

\footnotetext{
1 Department of Housing environmental design, College of Human Ecology, Chonbuk National University, Jeonju 561-756, Korea

2 Laboratory of Wood Science, Division of Sustainable Bioresources Science, Faculty of Agriculture, Kyushu University, Fukuoka 812-8581, Japan

* Corresponding author (E-mail: gckim@jbnu.ac.kr)
}

cal developments can prevent this problem. Hanok has been unstably constructed in which purlines were placed across an unsettled rectangular structure as part of the joint method for ieum and machoom. Due to the machoom of tenon and mortise, Hanok is very stable for swelling and twisting, and can support vertical loading. Frames of Hanok mainly consist of post, beam and purlines made of wood. The following house type was called wooden framed construction. To understand the structure of Hanok, an appreciation of post, beam and purline is necessary.

Although wood offers many advantages as structural members, its limited dimensions necessitated its use with joints for the sake of convenience. The term 'joint', which means the way in which one member is made with two or more members, can be classified into three categories in Korea: jokmae (a kind of parquet) means adding into sides of boards or panles, machoom means a joint of members in a T-shape or at a certain angle such as post and beam, purlin and post, or brace and post, post and foundation, and ieum means a joint of members along the members' direction such as post and post, or beam and beam. Ancient Koreans followed some principles in using ieum and machoom. For good jointing of wooden framed construction, as little cutting as possible is made, and jointed at a point subjected to only a small stress, and not crafted for decoration. The ending of joints should be fitted tightly to transfer stress equally, and the cross-section of the joints should be perpendicular to the stress direction.

In Korea, an apprentice system was prevalent instead of the transfer of systematic and scientific theories and techniques for traditional constructions. For this reason, mechanical and physical data for traditional joints do not 
exist in spite of the continued presence of many Hanok. To systematically and scientifically advance the Hanok which is not merely ancient structures but also the spirit and soul of Korea, some studies are necessary to understand the basic physical and mechanical properties of the principal traditional joints that are unique to Hanok.

Ieum and machoom of Joomeokjang, which have been used most widely in Korea, are not just a simple joint method but a well functioning joint method with proper mechanical performance. As the Joomeokjang and Nabijang joints were considered the most basic and important joint method in terms of mechanical performance, it is necessary to specifically investigate their joint patterns.

To appreciate the bending performance of the four types of traditional joints widely used in Korea, Nabijang, Joomeokjang, a pair of double Joomeokjang, and cross shaped joint were tested in this study. A control specimen with no joint was also examined for comparison.

\section{MATERIALS AND METHODS}

The bending test was conducted according to KSF 2150:2004. The span of the specimen should be more than 15 times its depth, and its total length should be its span plus two times its depth, as stated in KSF 2150, but these conditions could not be met due to the difficulties in preparing a full-scale traditional joint.

However, as the main study goal was to estimate the mechanical performance of the Korean traditional joint, a test was conducted to evaluate the bending strengths of Korean traditional joints in comparison to control specimens of the same dimensions. Also, a test was conducted to identify those joints with superior performance among the traditional joints.

The wood species of the specimens was Japanese larch. The loading speed for all specimens was $5 \mathrm{~mm} / \mathrm{min}$, according to KSF 2150 . The cross section was $80 \times 80 \mathrm{~mm}$ and the length was $600 \mathrm{~mm}$ for all joints. Only the cross
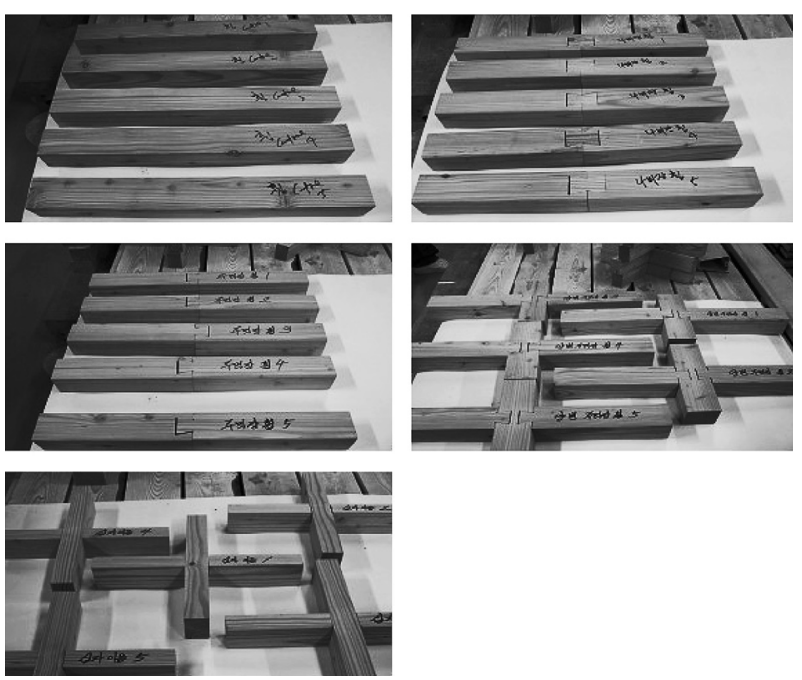

Fig. 1. The features of traditional joint specimen (From left top; Control, Nabijang Joomeokjang, Pair of double Joomeokjang, Cross shaped joint). shaped joint was $400 \mathrm{~mm}$ long because of manufacturing difficulties. For the Joomeokjang joint, the width and height of the tenon's protrusion were $50 \mathrm{~mm}$ and $20 \mathrm{~mm}$, respectively, and the width of the base was $30 \mathrm{~mm}$. To compare the capacity for the Joomeokjang, the dimensions of the Nabijang joint were also the same as those of Joomeokjang. The span for all traditional joints was $400 \mathrm{~mm}$, except for the cross shaped joint which had a span of $300 \mathrm{~mm}$. As the main objective of this study was to compare the relative bending property among traditional Korean joints, each joint was only subjected to 5 test repetitions.

There is no special testing standard for evaluating the bending performance of traditional Korean joints. The position of traditional joints in Hanok should be placed in a post or other structural member. Therefore, the resistance of the jointed member to lateral loading might be more important than its bending performance to vertical loading on the jointed section. Therefore, the loading direction was applied as shown in Fig. 2.
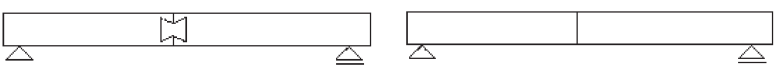

Fig. 2. Loading configuration of Korean traditional joints (Left: Side view, Right: Upside view).

\section{RESULTS AND DISCUSSION}

The members for the main target of this study were dori (Korean term: a kind of purline), changbang (Korean term: a kind of connecting member between post and post by Joomeokjang joint), booyeon (Korean term: extended eaves), and yeonmok (Korean term: a kind of rafter). Those members were all affected by bending performance. As a rule, the parts that are important for the bending performance are also important for tensile performance rather than compressive performance.

\section{Comparison of bending performances for Korean traditional joints}

The load-deformation curve for the Joomeokjang and Nabijang joints are shown in Figs. 3 and 4, respectively. Rupture occurred when maximum deformation exceeded $15 \mathrm{~mm}$ through the ultimate load pass by the proportional limit point.

Typical load-deformation curves for the pair of double Joomeokjang and cross shaped joint are shown in Figs. 5 and 6 . Both joints were ruptured immediately after reaching ultimate strength at around $6 \mathrm{~mm}$ deformation.

The Joomeokjang and Nabijang joints are manufactured by ieum, and the pair of double Joomeokjang and cross shaped joints are produced by machoom. The longitudinally jointed ieum therefore showed more deformation than the vertically jointed machoom and failed.

The bending strength of ieum, which has only one direction joint, exhibited a ultimate strength ranged from $2000 \mathrm{~N}$ to $2500 \mathrm{~N}$. However, machoom, which has both 
side joints, showed a ultimate strength ranging from $3000 \mathrm{~N}$ to $3500 \mathrm{~N}$ in the pair of double Joomeokjang, and showed a ultimate strength of $8500 \mathrm{~N}$ in the cross shaped joint. Accordingly, the bending strength of machoom was greater than that of ieum. The connections in Hanok are usually machoom joint, which has a sufficient bending performance. Moreover, since the connection of post and beam in Hanok is not a rigid joint but a hinge joint, so the stiffness of connections in Hanok is sufficient to resist an earthquake.

MOR and MOE values for the five groups, including the four types of traditional joint plus the control specimen, are presented in Tables 1 and 2. As mentioned previously, a sufficient span could not be attained according to KSF 2150:2004 for the bending test, so the bending strength of the control specimen was lower than the standard value. However, as the main goal of this study was to make a relative comparison of the bending performance among some Korean traditional joints, the same length and cross sections of each joint were only satisfied for the comparison (only the dimensions of the cross shaped joint were different from those of the other joints due to the manufacturing difficulty).

The MORs of the Joomeokjang and Nabijang joints were $2.35 \mathrm{MPa}$ and $2.42 \mathrm{Mpa}$, respectively, corresponding to $5.88 \%$ and $6.05 \%$ of the $39.99 \mathrm{MPa}$ value of the bending performance of the control specimen. The result was considerably low compared to the previous compression test where the Joomeokjang and Nabijang joints showed $47 \%$ and $55 \%$ of the performance of the control specimen (submitted to Wood \& Fiber Science: A study on the compressive strength properties of traditional Korean joints).

Because no other treatment for increasing the joint performance except traditional ieum and machoom method was used in this study, the bending performance can be increased by using adhesive or supplementary wedge. However, the main study purpose was to evaluate the relative structural performance of Korean traditional joints and identify the best joint, in order to improve the jointing ability.

Methods to improve the jointing ability will be investigated in future study. The strength of the Joomeokjang and Nabijang joints was considerably reduced compared to the control specimen, and the bending performance of Nabijang was better that that of Joomeokjang when only their mean strength was compared. This result corresponded to a previous compression test showing that the compression performance of Nabijang was better than that of Joomeokjang (submitted to Wood \& Fiber Science: A study on the compressive strength properties of traditional Korean joints).

In the compression test results, the mean strength of Nabijang was better than that of Joomeokjang, but the difference was not statistically significant. Joomeokjang was more efficient than Nabijang considering the failure types. Hence, statistical analysis and understanding of failure types for bending test were also added to this study.

The MOEs of the Joomeokjang and Nabijang joints were $178.82 \mathrm{MPa}$ and $151.19 \mathrm{MPa}$, respectively, which were $11.2 \%$ and $9.5 \%$ of the $1593.70 \mathrm{MPa}$ value of the control specimen. Comparing only the mean values, the compressive strength and MOR of Nabijang were better than those of Joomeokjang, but one MOE result of Joomeokjang was higher than that of Nabijang. These

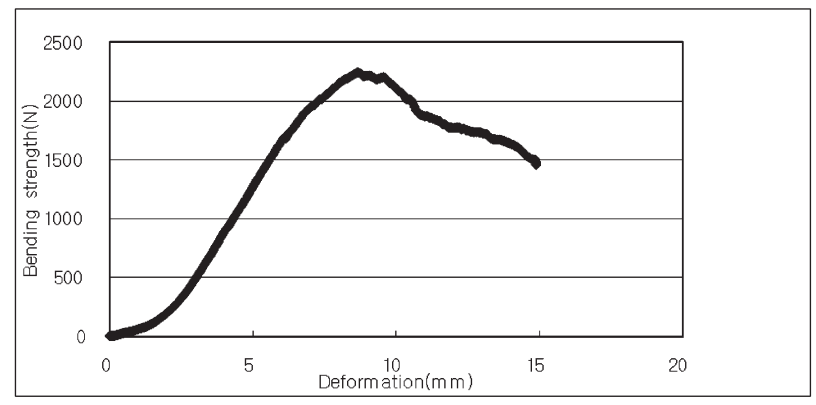

Fig. 3. Load-deformation curve for the Joomeokjang joint (Specimen No. 5)

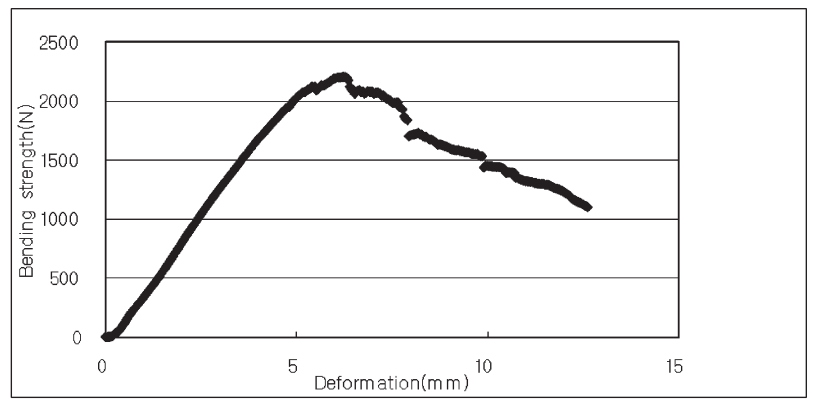

Fig. 4. Load-deformation curve for the Nabijang joint (Specimen No. 3).

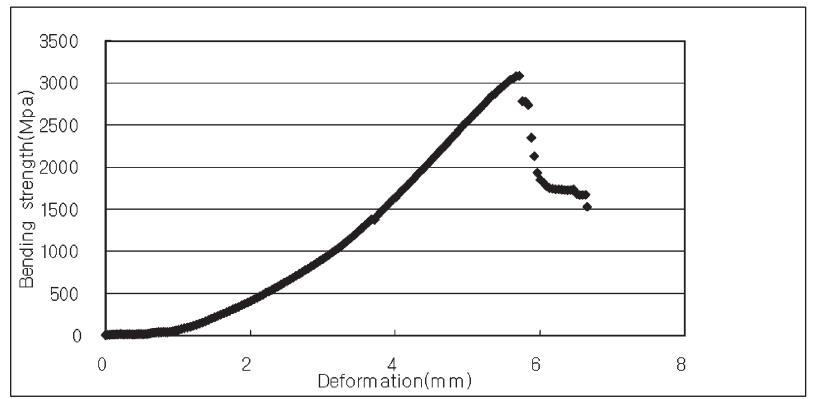

Fig. 5. Load-deformation curve for the Pair of double Joomeokjang joint (Specimen No. 5).

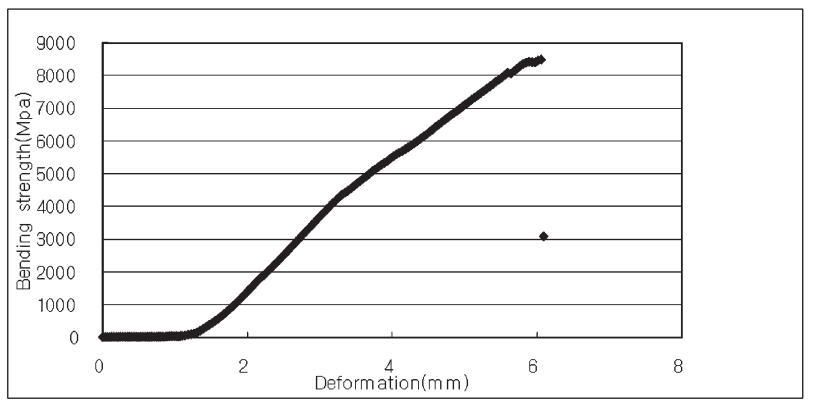

Fig. 6. Load-deformation curve for the Cross shaped joint (Specimen No. 1). 
results suggested that the Joomeokjang joint is better than the Nabijang joint for Hanok, which comprises not rigid joints but hinge joints, because Joomeokjang had greater stiffness than Nabijang.

The MOR of the pair of double Joomeokjang and cross shaped joints where the members meet in the rectangular direction was lower than that of the control specimen, but higher than that of ieum where the members meet along the same direction. The performance of the pair of double Joomeokjang was $10.1 \%$ of that of the control specimen, and that of the cross shaped joint was $68.2 \%$ of that of the control specimen. The span used for the cross shaped joint was $300 \mathrm{~mm}$, which was different from the $400 \mathrm{~mm}$ span of the other joints. Therefore, although it was impossible to compare the values directly, we assumed that the bending performance was considerably higher than that of the pair of double Joomeokjang.

The MOE of machoom was higher than that of ieum. The MOE of the cross shaped joint was especially higher than that of the control specimen. The MOE value of the pair of double Joomeokjang was $12.4 \%$ of that of the control specimen, and the MOE value of the cross shaped joint was $135.3 \%$ of that of the control specimen.

The fitness of the contacting area between the members for cross shaped joint was considered superior to that of the Joomeokjang and Nabijang joints, and mutual compression occurred when the bending was loaded, thereby improving the stiffness. More accurate study is needed for more detailed results. However, based on these results the cross shaped joint is recommended as a good joint method in Hanok that features a hinge-type joint because the cross shaped joint has better stiffness than the other joint methods.

Table 1. Comparison of MOR for among the Korean traditional joints. (Unit: MPa)

\begin{tabular}{cccccr}
\hline & & & & Pair of double \\
& Control Joomeokjang & $\begin{array}{c}\text { Cross } \\
\text { shaped } \\
\text { joint }\end{array}$ \\
\hline & 39.97 & 1.78 & 2.33 & 1.93 & 23.59 \\
& 42.06 & 2.33 & 2.42 & 2.92 & 2.95 \\
& 38.76 & 1.64 & 2.58 & 3.12 & 24.78 \\
& 43.21 & 3.36 & 2.99 & 3.80 & 15.36 \\
& 35.95 & 2.63 & 1.78 & 3.62 & 24.51 \\
Avg. & 39.99 & 2.35 & 2.42 & 3.07 & 18.24 \\
St.de. & 2.85 & 0.69 & 0.44 & 0.73 & 9.39 \\
\hline
\end{tabular}

Table 2. Comparison of MOE for among the Korean traditional joints. (Unit: MPa)

\begin{tabular}{rrrrr}
\hline Control Joomeokjang & Nabijang & $\begin{array}{c}\text { Pair of double } \\
\text { Joomeokjang }\end{array}$ & $\begin{array}{c}\text { Cross } \\
\text { shaped } \\
\text { joint }\end{array}$ \\
\hline 1501.69 & 114.94 & 209.77 & 132.03 & 3621.30 \\
1685.74 & 153.78 & 160.35 & 201.56 & 299.07 \\
1305.66 & 203.52 & 145.31 & 151.76 & 2638.58 \\
1923.18 & 286.46 & 167.66 & 316.41 & 1952.78 \\
1552.25 & 135.39 & 72.85 & 186.52 & 2270.99 \\
Avg. 1593.70 & 178.82 & 151.19 & 197.66 & 2156.54 \\
St.de. 229.22 & 68.54 & 49.89 & 71.86 & 1212.71 \\
\hline
\end{tabular}

Statistical analysis of the bending performance differences of the traditional joint

Analysis of significant differences among traditional joints

The MORs and MOEs for traditional joints and the control specimen are shown in Fig. 7, respectively. As mentioned previously, the bending performance of machoom was better than that of ieum when only the mean values were considered. For the machoom joint, both MOR and MOE of the cross shaped joint were higher than those of the pair of double Joomeokjang. The MOR of Nabijang was higher than that of Joomeokjang but MOE exhibited the opposite tendency for the ieum joint. However, further statistical analysis of each group in comparison to a previous study of the compression test is required (submitted to Wood \& Fiber Science: A study on the compressive strength properties of traditional Korean joints).

There was a low necessity for the cross shaped joint because it showed much better performance than the other joints, but Joomeokjang, Nabijang and the pair of double Joomeokjang cannot be confidently compared only on the basis of the mean values. Hence, analysis of variance statistical analysis was conducted for all groups.

From Table 3, the much higher F-value of 69.2 compared to the rejection limit of 2.87, and the very low level of significance at $2 \mathrm{E}-11$, supported the possibility of significant differences among the groups. In other words, there were statistical differences of MOR between the four types of traditional joints and the control specimen.

According to Table 4, the analysis of variance for MOE showed that the F value of 14.8 was higher than the rejection limit of 2.87 and that the level of significance was very low, which was the same tendency as MOR. This result supported the possibility of a significant difference among the groups. Namely, the MOE of each traditional joint differed significantly. However, Joomeokjang and Nabijang in ieum have similar appearance and uses, and the pair of double Joomeokjang and cross shaped joints also have similar appearance and uses in machoom. Consequently, the ieum and machoom groups had to be separated for additional comparison and investigation of the bending performances among the groups.

Analysis of significant differences among the traditional ieum joints

The F-test should be conducted in advance to identify the significance of the difference between the two groups and then verify the equal variance or unequal variance of the groups. The significance between the two groups can be judged through the t-test based on that verification. The t-test for the MOR of Joomeokjang and Nabijang was conducted after the F-test and the results are shown in Table 5.

The level of significance of the F-test was 0.19 , which was higher than 0.05. Therefore, the t-test, based on the assumption of equal variance for the bending performances between the two groups, was carried out to clarify the significant difference. The results are shown in Table 6. The level of significance exceeding 0.05 

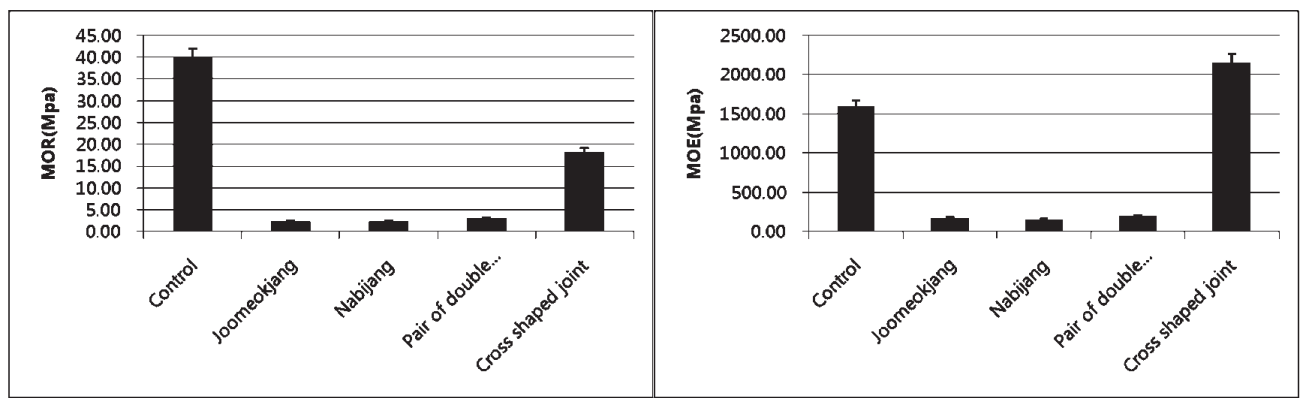

Fig. 7. Comparison of MOR and MOE among the Korean traditional joints.

Table 3. ANOVA table for MOR of the Korean traditional joints

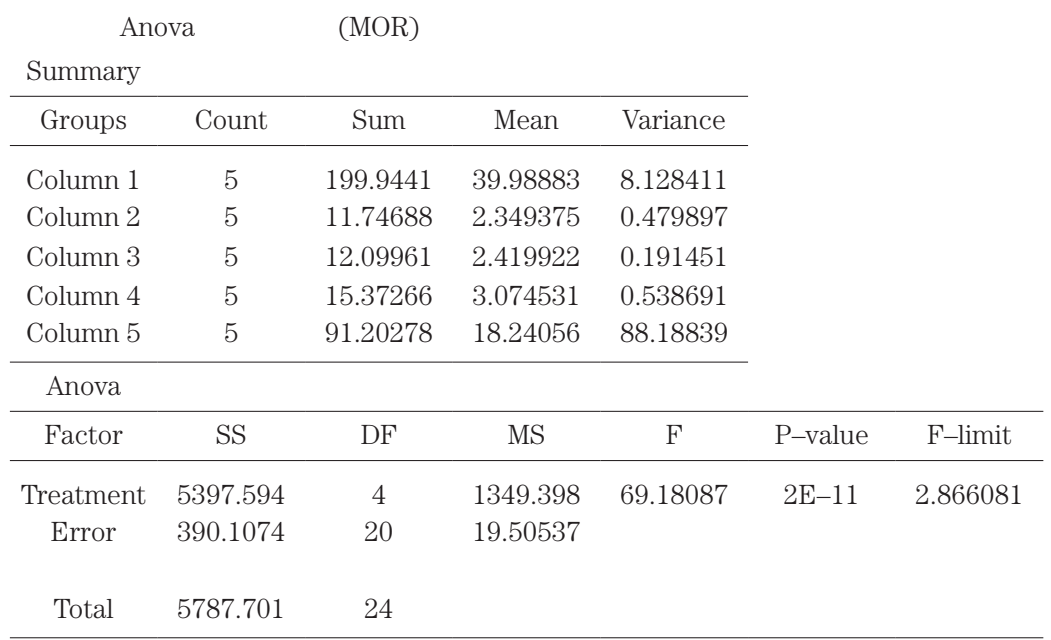

Table 4. ANOVA table for MOE of the Korean traditional joints

\begin{tabular}{|c|c|c|c|c|c|c|}
\hline \multirow{2}{*}{\multicolumn{2}{|c|}{$\begin{array}{l}\text { Anova } \\
\text { Summary }\end{array}$}} & \multicolumn{3}{|l|}{ (MOE) } & & \\
\hline & & & \\
\hline Groups & Count & Sum & Mean & Variance & & \\
\hline Column 1 & 5 & 7968.522 & 1593.704 & 52543.85 & & \\
\hline Column 2 & 5 & 894.082 & 178.8164 & 4697.417 & & \\
\hline Column 3 & 5 & 755.9375 & 151.1875 & 2489.408 & & \\
\hline Column 4 & 5 & 988.2813 & 197.6563 & 5163.517 & & \\
\hline Column 5 & 5 & 10782.72 & 2156.543 & 1470668 & & \\
\hline \multicolumn{7}{|l|}{ Anova } \\
\hline Factor & SS & $\mathrm{DF}$ & MS & $\mathrm{F}$ & $\mathrm{P}$-value & F-limit \\
\hline Treatment & 18121872 & 4 & 4530468 & 14.75182 & $9.15 \mathrm{E}-06$ & 2.866081 \\
\hline Error & 6142248 & 20 & 307112.4 & & & \\
\hline Total & 24264119 & 24 & & & & \\
\hline
\end{tabular}

revealed the absence of any statistically significant differences between the Nabijang and Joomeokjang joints.

There were no statistically significant differences between Joomeokjang and Nabijang through the t-test of MOE based on the assumption of equal variance because the level of significance exceeded 0.05, as shown in Table 8. As in the MOR results, there were no statistically significant differences between them. Therefore, the bending performance could not be compared between
Joomeokjang and Nabijang only with the mean value, and additional information such as failure type should be included.

Analysis of significant differences among traditional machoom joints

As with the previous ieum joints, the F-test was conducted in advance to identify the level of significance between the two groups and then verify that the groups had equal variance or unequal variance for the pair of 
Table 5. F-test result for MOR between the Joomeokjang joint and Nabijang joint

F-test: two sample for variance

\begin{tabular}{ccc}
\hline & Variable 1 & Variable 2 \\
\hline mean & 2.349375 & 2.419922 \\
variance & 0.479897 & 0.191451 \\
observations & 5 & 5 \\
DF & 4 & 4 \\
F & 2.506628 & \\
$\mathrm{P}(\mathrm{F}<=$ f) one-sided test & 0.19759 & \\
F limit: one-sided test & 6.388233 & \\
\hline
\end{tabular}

Table 6. t-test result for MOR between the Joomeokjang joint and Nabijang joint

t-test: assuming equal variance

\begin{tabular}{ccc}
\hline & Variable 1 & Variable 2 \\
\hline mean & 2.349375 & 2.419922 \\
variance & 0.479897 & 0.191451 \\
observations & 5 & 5 \\
Pooled variance & 0.335674 & \\
DF & 0 & \\
t value & 8 & \\
Hypothesized mean difference & -0.19253 & \\
F limit: one-sided test & 0.426064 & \\
P $(\mathrm{F}<=$ f) two-sided test & 1.859548 & \\
F limit: two-sided test & 0.852128 & \\
\hline
\end{tabular}

Table 7. F-test result for MOE between the Joomeokjang joint and Nabijang joint

F-test: two sample for variance

\begin{tabular}{ccc}
\hline & Variable 1 & Variable 2 \\
\hline mean & 178.8164 & 151.1875 \\
variance & 4697.417 & 2489.408 \\
observations & 5 & 5 \\
DF & 4 & 4 \\
F & 1.886962 & \\
$\mathrm{P}(\mathrm{F}<=$ f) one-sided test & 0.276827 & \\
$\mathrm{~F}$ limit: one-sided test & 6.388233 & \\
\hline
\end{tabular}

Table 8. t-test result for MOE between the Joomeokjang joint and Nabijang joint

\begin{tabular}{ccc}
\multicolumn{3}{c}{ t-test: assuming equal variance } \\
\hline & Variable 1 & Variable 2 \\
\hline mean & 178.8164 & 151.1875 \\
variance & 4697.417 & 2489.408 \\
observations & 5 & 5 \\
Pooled variance & 3593.413 & \\
Hypothesized mean difference & 0 & \\
DF & 8 & \\
t value & 0.728753 & \\
P(F<=f) one-sided test & 0.243468 & \\
F limit: one-sided test & 1.859548 & \\
P(F<=f) two-sided test & 0.486936 & \\
F limit: two-sided test & 2.306004 & \\
\hline
\end{tabular}

Table 9. F-test result for MOR between the Pair of double Joomeokjang joint and Cross shaped joint

F-test: two sample for variance

\begin{tabular}{ccc}
\hline & Variable 1 & Variable 2 \\
\hline mean & 3.074531 & 18.24056 \\
variance & 0.538691 & 88.18839 \\
observations & 5 & 5 \\
DF & 4 & 4 \\
F & 0.006108 & \\
$\mathrm{P}(\mathrm{F}<=$ f) one-sided test & 0.00011 & \\
F limit: one-sided test & 0.156538 & \\
\hline
\end{tabular}

Table 10. t-test result for MOR between the Pair of double Joomeokjang joint and Cross shaped joint

t-test: assuming unequal variancee

\begin{tabular}{ccc}
\multicolumn{3}{c}{ t-test: assuming unequal variancee } \\
\hline & Variable 1 & Variable 2 \\
\hline mean & 3.074531 & 18.24056 \\
variance & 0.538691 & 88.18839 \\
observations & 5 & 5 \\
DFpothesized mean difference & 0 & \\
t value & 4 & \\
P(F<=f) one-sided test & 0.011377 & \\
F limit: one-sided test & 2.131847 & \\
P(F<=f) two-sided test & 0.022754 & \\
F limit: two-sided test & 2.776445 & \\
F limit: two-sided test & 2.306004 & \\
\hline
\end{tabular}

Table 11. F-test result for MOE between the Pair of double Joomeokjang joint and Cross shaped joint

F-test: two sample for variance

\begin{tabular}{ccc}
\hline & Variable 1 & Variable 2 \\
mean & 197.6563 & 2156.543 \\
variance & 5163.517 & 1470668 \\
observations & 5 & 5 \\
DF & 4 & 4 \\
F & 0.003511 & \\
$\mathrm{P}(\mathrm{F}<=$ f) one-sided test & $3.66 \mathrm{E}-05$ & \\
$\mathrm{~F}$ limit: one-sided test & 0.156538 & \\
\hline
\end{tabular}

Table 12. t-test result for MOE between the Pair of double Joomeokjang joint and Cross shaped joint t-test: assuming unequal variance

\begin{tabular}{ccc}
\hline & Variable 1 & Variable 2 \\
\hline mean & 197.6563 & 2156.543 \\
variance & 5163.517 & 1470668 \\
observations & 5 & 5 \\
DF & 0 & \\
t value & 4 & \\
Hypothesized mean difference & -3.60559 & \\
P(F < =f) one-sided test & 0.011323 & \\
P (F< limit: one-sided test & 2.131847 & \\
F limit: two-sided test & 0.022645 & \\
\end{tabular}


double Joomeokjang and cross shaped joints. The t-test was conducted after completion of the F-test.

The t-test, assuming unequal variance, was conducted because the level of significance was less than 0.05. The previous conclusion of unequal variance for machoom but equal variance for ieum implied that a severe difference of characteristics for the pair of double Joomeokjang and cross shaped joints. The results of the t-test are shown in Table 10. The significant differences between two groups implied a considerably difference between the pair of double Joomeokjang and cross shaped joints for MOR.

The F-test results of MOE for the pair of double Joomeokjang and cross shaped joints are shown in Table 11. The t-test assuming unequal variance was conducted because the level of significance was less than 0.05 .

The two groups exhibited a significant different with a level of significance of less than 0.05 , according to the t-test results shown in Table 12.

The pair of double Joomeokjang and cross shaped joints differed not only in terms of the mean values but also in terms of the statistically significant difference. This confirmed the superiority of the cross shaped joint over the pair of double Joomeokjang joints for the Hanok construction. Naturally, the failure types must also be considered for the machoom joints such as the ieum joint.

\section{Comparison of failure types for traditional joints}

Although there were no specific failure types, a complex failure type comprising a mix of simple tension, horizontal shear and cross grain failure was developed in the control specimen. On the other hand, cross grain failure was dominant for the Joomeokjang and Nabijang joints. Simple tension failure was developed in all of the pair of double Joomeokjang while the cross shaped joint
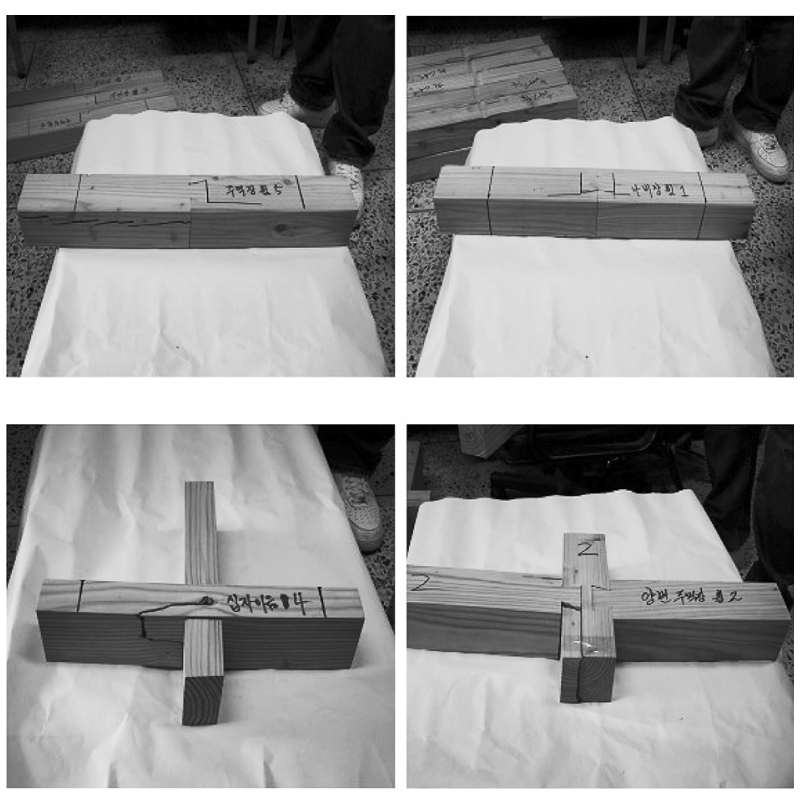

Fig. 8. Failure types for each Korean traditional joints. (Joomeokjang joint; Nabijang joint; Cross shaped joint; Pair of double Joomeokjang joint). showed a mixture of simple tension failure and cross grain failure.

Some of the types of failure are presented in Fig. 8. According to these results, the Joomeokjang and Nabijang joints should not be used in the possible failure of cross grain, nor the pair of double Joomeokjang and cross shaped joints in the possible failure of simple tension failure.

\section{CONCLUSION}

Hanok, a Korean traditional house constructed without nails or adhesive, is durable due to its different construction techniques compared to the typical western house. However, an apprentice system was prevalent in Korea instead of the transfer of systematical and scientific theories and techniques for traditional constructions. Therefore, few data have been accumulated for the mechanical and physical properties of traditional joints.

Since the Joomeokjang and Nabijang joints are the most basic jointing method in Korea traditional building construction, their jointing pattern warrants further investigation. In this study, the bending performances for four types of widely used Korean traditional joint, Joomeokjang, Nabijang, pair of double Joomeokjang and cross shaped joint, were evaluated.

For ieum joints, the MOR of Nabijang was higher than that of Joomeokjang, and the MOE of Joomeokjang was higher than that of Nabijang; however, there were no significant differences between the two methods. Therefore, the performance of Joomeokjang and Nabijang could not be compared only with the mean values, and additional information such as failure type is necessary.

For machoom joints, the pair of double Joomeokjang was statistically superior to the cross shape joint in terms of both mean values and the statistical analysis for MOE and MOR. Needless to say, the failure types of machoom joints should be sufficiently considered such as ieum joints.

The failure types of Joomeokjang and Nabijang mainly consisted of cross grain failure. Simple tension failure was developed in the pair of double Joomeokjang and cross shaped joints, which created a mixed failure of simple tension failure and cross grain failure.

The dimensional variation of the Joomeokjang or Nabijang joints needs to be further evaluated in future study in order to determine the optimum performance. In other words, the performance of various tenon sizes for Joomeokjang and of various wedge sizes for Nabijang should be further investigated, as should the performance of various cross section sizes for the cross shaped joint.

\section{ACKOWLEDGEMENT}

This paper was supported by research funds of Chonbuk National University in 2011. 


\section{REFERENCES}

Gwang-Chul Kim. et al. 2010 A study on the compressive strength properties of traditional Korean joints. J. Fac. Agr., Kyushu Univ. 55(2): 307-312

Hwang, J. K. et al. 2006 A classification of structural type for traditional wooden frame considering the flow of force. J. of the Architectural Institute of Korea. Structure \& Construction. 22(2): 35-41

Jeong M. S. et al. 1999 Static and cyclic behavior of wooden frames with tenon joints under lateral load. J. of structural engineering. $\mathbf{1 2 5}$ (3): 344-349

Jung, S. J. et al. 2005 A study on the modeling method for the analysis of the Korean traditional wooden frame. J. of the Architectural Institute of Korea. Structure \& Construction.
21(12): 77-84

Korean Standards. 2004 Method of flexure test for wood. KSF 2150: 2004

Lee, Y. W et al. 2006 An analytical modeling of the beam-direction frame of traditional wood structure system. J. of the Architectural Institute of Korea. Structure \& Construction. 22(3): 29-36

Lee, Y. W. et al. 2007 Capacity of lateral load resistance of doridirectional frame with janbu-connection in traditional wood structure system. J. of the Architectural Institute of Korea. Structure \& Construction. 23(2): 35-42

William M. B. et al. 1999 Behavior and modeling of woodpegged timber frames. $J$. of structural engineering. $125(1): 3-9$ 